\title{
THE LARVA OF A DIDEMNID ASCIDIAN, WITH NOTES ON THE STRUCTURE OF THE COLONY AND THE ADULT
}

\author{
By R. H. Millar \\ From the Marine Station, Millport
}

(Text-fig. I)

There are few adequate descriptions of British members of the ascidian family Didemnidae and little attention has been given to the larvae. In the autumn of 1947 a didemnid was collected from the intertidal zone in the Menai Strait, North Wales. This ascidian agrees superficially with Leptoclinum maculosum Edwards, as figured by Milne Edwards (I842) and by Alder \& Hancock (I905I9I2), although differing somewhat from the diagnosis of Didemnum maculosum (Edwards) given by Harant \& Vernières (1933). It is closer anatomically to the $D$. fulgens (Edwards) of Harant \& Vernières, but differs in colour. In most features the colony and zooid closely resemble the descriptions given by Michaelsen (I923) for his species D. helgolandicum Michaelsen, and it is probable that this is the species to which it should be assigned. Nevertheless, the name $D$. maculosum has been retained since it is under that name that it has probably appeared in most faunistic lists.

Until recently all accounts of didemnid larvae have described three anterior adhesive organs. This was the number given by Giard (1872) for Diplosoma gelatinosum Edwards, and by Lahille (1890) for Trididemnum tenerum Verrill and Polysyncraton lacazei Giard. Berrill (1947), however, has described a new species of didemnid, Trididemnum alleni Berrill, the larva of which has only two anterior adhesive organs, a condition not previously found in any ascidian larva.

The larva (Fig. I A) of the colonies found in the Menai Strait resembles that of $T$. alleni in many features. The trunk is about $0.35 \mathrm{~mm}$. long from the tip of the adhesive organs to the base of the tail. The sensory vesicle is prominent and contains an anterior static organ and a posterior ocellus. Four rows of stigmata in the branchial sac rudiment distinguish the larva from that of T. alleni which has only three rows. There are eight ectodermal ampullae in the anterior and ventral part of the trunk and, as in T. alleni, there are only two anterior adhesive organs, one dorsal and one ventral. The larva of Didemnum maculosum has therefore features in common with the larvae of most members of the family Didemnidae (four rows of stigmata), and also features in common with the larva of Trididemnum alleni (two anterior adhesive organs). 

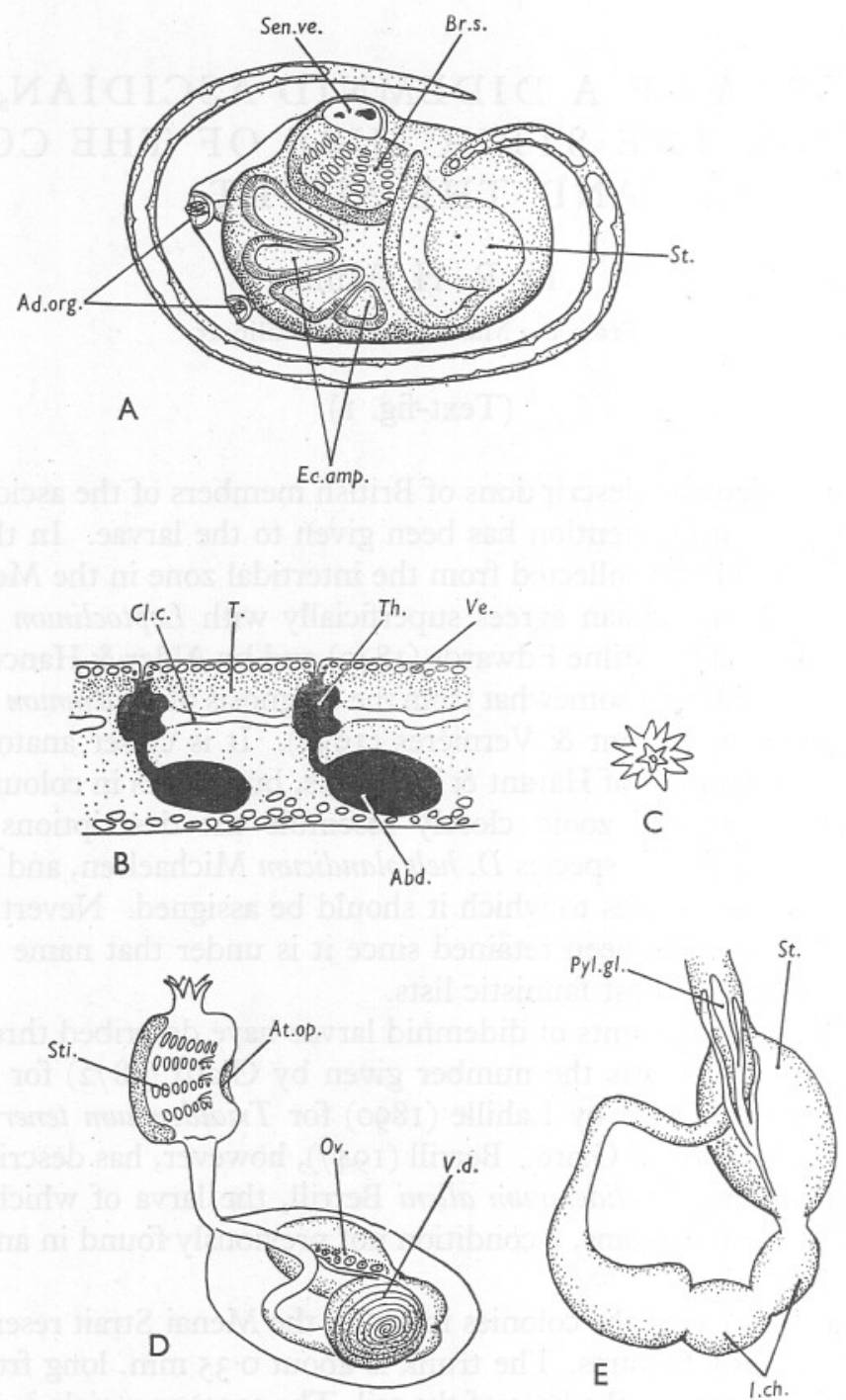

Fig. I. Didemnum maculosum auctt. A, larva, seen from the left, as it appears when removed from the egg follicles. B, section through part of a colony showing the arrangement of the zooids in the common test. C, a spicule from the common test. D, zooid. E, the abdominal part of the alimentary canal.

Abd., abdomen of the zooid; Ad.org., anterior adhesive organs; At.op., atrial opening; Br.s., branchial sac; Cl.c., cloacal canal of the common test; Ec.amp., ectodermal ampullae; I.ch., first two chambers of the intestine; Ov., ovary; Pyl.gl., pyloric gland; Sen.ve., sensory vesicle; St., stomach; Sti., stigmata; T., common test of the colony; Th., thorax of the zooid; V.d., vas deferens; Ve., vesicle of the common test. 
The colonies (Fig. I B) formed large encrusting sheets about $0.5 \mathrm{~mm}$. in thickness. The colour is light grey to buff, marked with streaks and spots of dark grey and purplish black. Small prominences are evenly scattered over the surface, which is also marked by deep slit-like depressions hollowed out and inhabited by the amphipod Tritaeta gibbosa (Bate). The dark streaks marking the colony are due to the accumulation of faecal pellets in the cloacal system of the common test, and the markings presumably become more extensive and distinct as the colony grows older. Neither oral nor atrial openings are prominent on the surface of the colony. Sections show that the most superficial part of the test is occupied by a layer of large vesicles up to $40 \mu$ in diameter. Below these is a dense mass of white calcareous spicules (Fig. IC) which give the colony its light colour. The spicules, which also extend in smaller numbers through the lower layers of the test, are about $25 \mu$ in diameter, and have about 30 rays. A cloacal system of irregular channels exists within the common test, and into these channels open the atrial cavities of the zooids. In the lower part of the test there are often many large vesicles similar to those of the upper layers. In sectioned material a narrow channel is seen to lead from the upper surface of the test down to the oral siphon of each zooid, which lies a little below the surface. It is not certain whether this deep position of the oral siphon is an artefact produced in fixation.

A zooid is figured in Fig. I D. The thorax lies approximately at right angles to the surface of the test. There are six pointed triangular lobes on the oral siphon and the atrial opening is a wide elliptical slit across the dorsal surface of the thorax, with no siphon. Four rows of stigmata lie on each side of the branchial sac and each row has about eight stigmata. The lateral thoracic organs are not conspicuous. A narrow stalk of moderate length joins the thorax to the abdomen, which is twice as long as the thorax and lies approximately at right angles to the lower surface of the test. The oesophagus is long, but not so long as that of Trididemnum alleni, and the large round stomach leads into the first of three chambers of the intestine. The first two of these chambers are small, ovoid and equal; the third is a large pear-shaped sac tapering to the narrow intestinal loop. Close beside the oesophagus lies the rectum, which is enveloped by a simple pyloric gland. The eight to nine coils of the spiral vas deferens lie on the side of the single testis, and the ovary is situated close to the stomach and part of the intestine.

The adult of this didemnid differs clearly enough from that of $T$. alleni to prevent confusion, especially in the possession of six oral lobes and four rows of stigmata. It belongs to the genus Didemnum and is almost certainly the species referred to as $D$. maculosum in most faunistic lists. This species, although common, does not appear to have been described previously in the larval stage, and there seems to be need of further investigation of the larvae of the family Didemnidae. 


\section{REFERENCES}

Alder, J. \& HANCock, A., I905-I9I2. The British Tunicata, Vol. 3, pp. I-II2.

BerriLl, N. J., I947. The ascidians Trididemnum alleni and Distaplia garstangi, new species from the Plymouth area. Fourn. Mar. Biol. Assoc., Vol. 26, pp. 609-I5.

EDWARDS, H. M., I842. Observations sur les Ascidies composées des côtes de la Manche. Mém. Acad. Sci. Fr., T. 18, pp. 217-326.

Giard, A. M., I872. Recherches sur les Ascidies composées ou Synascidies. Arch. Zool. Exp., T. I, pp. 50I-709.

Harant, H. \& Vernières, P., I933. Tuniciers, in Faune de France, T. 27, pp. I-99. Paris.

Lahille, F., I890. Contributions à l'Étude Anatomique et Taxonomique des Tuniciers. $528 \mathrm{pp}$.

Michaelsen, W., I923. Die Botrylliden und Didemniden der Nordsee. Wiss. Meeresunters. Helgoland, Bd. I4, pp. 97-I24. 